\title{
Knowledge on thalassaemia among students aged 14-17 years in Kurunegala district, Sri Lanka
}

\author{
*R Warushahennadi ${ }^{1}$, A K W Priyadarshani ${ }^{2}$, W D G H Wanasundara ${ }^{2}$, S A M A M Abeysekara ${ }^{2}$, J M \\ Nilam ${ }^{3}$
}

Sri Lanka Journal of Child Health, 2021; 50(2): 261-265

\begin{abstract}
Introduction: Prevention and control of thalassaemia in a country needs public education to prevent marriages between carriers. Correct message has to be delivered to the community so that the public will understand the importance of prevention. Kurunegala is one of the districts in Sri Lanka where thalassaemia is highly prevalent.
\end{abstract}

Objectives: The aim of this study was to assess the knowledge on thalassaemia of school children aged 14-17 years in Kurunegala district, Sri Lanka.

Method: Descriptive cross-sectional study. Using probability proportional to size sampling technique, 55 clusters of 30 students in age range 14-17 years each, were selected from all schools in Kurunegala district. Within each selected school, the required number of children was selected randomly.

Results: Out of the 1821 participants $92.6 \%$ had heard of thalassaemia before. Majority $(83.4 \%)$ of participants showed high knowledge score regarding thalassaemia. Age, gender, ethnicity and the type of school correlated with knowledge score.

Conclusions: Based on the study findings, students of Kurunegala district showed satisfactory level of knowledge regarding thalassaemia.

DOI: http://dx.doi.org/10.4038/sljch.v50i2.9568

${ }^{1}$ Consultant Haematologist, ${ }^{2}$ Medical Officer, National Thalassaemia Centre, Teaching Hospital, Kurunegala, ${ }^{3}$ Consultant Paediatrician, Teaching Hospital, Kurunegala

*Correspondence: rgodakandage@yahoo.com

https://orcid.org/0000-0002-2947-0394

(Received on 16 May 2020: Accepted after revision on 19 June 2020)

The authors declare that there are no conflicts of interest

Funding: Research grant - Second Health Development Project, Ministry of Health, Sri Lanka.

Open Access Article published under the Creative

Commons Attribution CC-BY (c) (i) License
(Key words: Thalassaemia, knowledge, students, Kurunegala district).

\section{Introduction}

Thalassaemia is considered the most common single gene disorder worldwide occurring with high frequency from the Mediterranean basin through the Middle East, Indian subcontinent, Burma and South East Asia, and Islands of Pacific ${ }^{1}$. Thalassaemia and other haemoglobinopathies are a significant public health problem in $71 \%$ of 229 countries worldwide. Over 330,000 affected infants are born annually (83\% sickle cell disorders, $17 \%$ thalassaemias). Haemoglobin disorders account for about $3.4 \%$ of deaths in children less than 5 years of age ${ }^{2}$. Globally, there are 269 million carriers of thalassaemia and 150 million $\beta$ thalassaemia alone, out of which 40 million are in South East Asia ${ }^{3}$. About $7 \%$ of pregnant women carry $\beta$ or $\alpha$ zero thalassaemia, or clinically significant haemoglobin, and over $1 \%$ of couples are at risk of having a thalassaemic baby ${ }^{2}$.

In Sri Lanka, prevalence of thalassaemia is higher in Kurunegala, Anuradhapura, Trincomalee and Hambantota districts ${ }^{4}$. In a recent nationwide survey on hospital based thalassaemia patients, 1774 patients with thalassaemia were identified in 23 different centres in Sri Lanka. Out of them, $68.7 \%$ had $\beta$ thalassaemia major and $20.3 \%$ had $\mathrm{Hb}$ $\mathrm{E} / \beta$ thalassaemia ${ }^{5}$. The management of these disorders require about $5 \%$ of the total health budget $^{6}$. Prevention and control of thalassaemia in a country needs public education, population screening, genetic counseling and antenatal diagnosis. The incidence of severe thalassaemia has been reduced by $96 \%$ in Cyprus, $62 \%$ in Italy, and $52 \%$ in Greece with these simple measures ${ }^{3,7}$.

In Sri Lanka, antenatal diagnostic facilities are not freely available and abortion of thalassaemic fetuses is not legalized. Therefore, the only measure to eradicate this genetic disorder is by public education and population screening. Screening individuals before marriage and advising the thalassaemia carriers to choose a non-carrier partner is the current way of prevention practised in Sri Lanka. National thalassaemia screening programme for school children and young adults (premarital screening) has been in place since 2005. School children are the future adults. It is 
important to educate them on thalassaemia, to prevent marriages between carriers, and to reduce future births of thalassaemia major children in Sri Lanka.

\section{Objectives}

This study was done to assess the awareness of thalassaemia and to describe the knowledge on thalassaemia among school children aged 14-17 years in Kurunegala district, Sri Lanka.

\section{Method}

Year of study: 2017-2018.

Study design: Descriptive cross sectional study.

Study setting: Kurunegala district, the capital city of North Western Province, Sri Lanka.

Study population: Children within 14-17 year age group studying in schools of Kurunegala district. There are 732 schools in Kurunegala district. The total number of school children within 14-17 year age group is 69,665 (statistics of Provincial Education office, Kurunegala-2015). Total population of Kurunegala district is 1.7 million (Census 2012).

Sample size determination: Since the expected proportion is not known, in order to arrive at the maximum sample size, it was taken as $50 \%$. When alpha error $=5 \%$, precision of the estimate $=5 \%$, cluster size $=30$, intra-cluster correlation coefficient $=0.1$, the design effect $=3.9$, and the non-response rate $=10 \%$, the required minimum sample size amounts to 1648 .

Sampling technique: Using probability proportional to size sampling technique, 55 clusters of 30 students in the age range 14-17 years each, were selected from all the schools in Kurunegala district. 54 schools were sampled (Two clusters from one school and one cluster from 53 schools). Within each school, the required number of children was selected randomly. If there were less than 30 students in the age range, 14-17 years in a particular school, all the children in the required age group were included in the study.
Inclusion and exclusion criteria: School children within the age group 14-17years studying and residing in Kurunegala district were included into the study. School children within the selected age group, studying in Kurunegala district but not residing there were excluded.

Study instruments: $\quad$ Self-administered questionnaire.

Data collection method: Participation in this study was voluntary. The self-administered questionnaire was administered to the participants to obtain demographic data.

Ethical Issues: The protocol was approved by the Ethical Review Committee of Teaching Hospital, Kurunegala (ERC/2015/16-ROI). Permission for the study was taken from the Provincial Director of Education, North Western Province and all the principals of selected schools. Written informed consent was taken from parents of the students and the students as well after reading out the information sheet and answering participants' questions by the researcher. A witness (a teacher/Principal) confirmed that the individual has given the consent freely.

Statistical analysis: Sample characteristics were analysed using descriptive statistical methods, and presented as percentages or proportions depending on their scales of measurements.

\section{Results}

A total of 1821 students aged between 14-17 years was selected for the present study. Fifty five clusters were selected from 54 schools (Two clusters x one school and one cluster x 54 schools). The study group was predominantly female $(59.9 \%)$. Of the participants, $57.7 \%$ were $14-15$ years old. Majority (93.6\%) were Sinhalese, 5.8\% were Muslim, $0.4 \%$ were Tamil and $0.2 \%$ were other ethnicities. A self-administered questionnaire was administered to the participants to obtain data. The questionnaire included two parts, demographic data and questions to assess knowledge on thalassaemia (Table 1). 
Table 1: Distribution of frequencies of responses for the questionnaire

\begin{tabular}{|c|c|c|c|}
\hline Variable & Response & frequency & $\%$ \\
\hline \multirow[b]{2}{*}{ 1. Have you ever heard of thalassaemia? } & Yes & 1687 & 92.6 \\
\hline & No & 134 & 7.4 \\
\hline \multirow{3}{*}{ 2. Thalassaemia is highly prevalent in Kurunegala. (Yes) } & Yes & 1295 & 71.1 \\
\hline & No & 39 & 2.1 \\
\hline & Don't know & 487 & 26.7 \\
\hline \multirow{3}{*}{ 3. Thalassaemia is inherited from parents. (Yes) } & Yes & 1608 & 88.3 \\
\hline & No & 43 & 2.4 \\
\hline & Don't know & 170 & 9.3 \\
\hline \multirow{3}{*}{ 4. Thalassaemia is a blood related disease. (Yes) } & Yes & 1662 & 91.3 \\
\hline & No & 24 & 1.3 \\
\hline & Don't know & 135 & 7.4 \\
\hline \multirow{3}{*}{$\begin{array}{l}\text { 5. Severe anaemia is the clinical presentation of Thalassaemia } \\
\text { major. (Yes) }\end{array}$} & Yes & 559 & 30.7 \\
\hline & No & 139 & 7.6 \\
\hline & Don't know & 1123 & 61.7 \\
\hline \multirow{3}{*}{ 6. Thalassaemia carriers are symptom free. (Yes) } & Yes & 899 & 49.4 \\
\hline & No & 318 & 17.5 \\
\hline & Don't know & 604 & 33.2 \\
\hline \multirow{3}{*}{ 7. Thalassaemia major children need blood transfusion.(Yes) } & Yes & 1002 & 55.0 \\
\hline & No & 113 & 6.2 \\
\hline & Don't know & 706 & 38.8 \\
\hline \multirow[t]{3}{*}{ 8. Thalassaemia carriers need blood transfusion. (No) } & Yes & 410 & 22.5 \\
\hline & No & 601 & 33.0 \\
\hline & Don't know & 810 & 44.5 \\
\hline \multirow{3}{*}{$\begin{array}{l}\text { 9. Thalassaemia carrier status can be diagnosed by a blood test. } \\
\text { (Yes) }\end{array}$} & Yes & 1758 & 96.5 \\
\hline & No & 9 & 0.5 \\
\hline & Don't know & 54 & 3.0 \\
\hline \multirow{3}{*}{$\begin{array}{l}\text { 10. A marriage between two thalassaemia carriers has a chance of } \\
\text { producing a thalassaemia major baby. (Yes) }\end{array}$} & Yes & 1637 & 89.9 \\
\hline & No & 37 & 2.0 \\
\hline & Don't know & 147 & 8.1 \\
\hline \multirow{3}{*}{$\begin{array}{l}\text { 11. A marriage between a thalassaemia carrier and a normal } \\
\text { individual has a chance of producing a thalassaemia major } \\
\text { baby. (No) }\end{array}$} & Yes & 281 & 15.4 \\
\hline & No & 1166 & 64.0 \\
\hline & Don't know & 374 & 20.5 \\
\hline \multirow{3}{*}{$\begin{array}{l}\text { 12. If one blood relative is diagnosed with thalassaemia, other } \\
\text { family members should also be screened. (Yes) }\end{array}$} & Yes & 1552 & 85.2 \\
\hline & No & 28 & 1.5 \\
\hline & Don't know & 241 & 13.2 \\
\hline
\end{tabular}

The correct answer is shown within brackets.

Great majority (92.6\%) of participants had heard of thalassaemia before. Majority $(71.1 \%)$ correctly stated that thalassaemia is highly prevalent in Kurunegala. Majority $(88.3 \%)$ knew that thalassaemia is inherited from parents. Great majority $(91.3 \%)$ correctly stated that thalassaemia is a blood related disease. Only $30.7 \%$ correctly stated that severe anaemia is the clinical presentation of thalassaemia major. $49.4 \%$ knew thalassaemia carriers are symptom free. Thalassaemia major children need blood transfusion was correctly stated by $55.0 \%$. Only $33.0 \%$ stated that thalassaemia carriers do not need blood transfusions. Great majority (96.5\%) correctly stated that thalassaemia can be diagnosed by a blood test. Majority $(89.9 \%)$ knew that a marriage between two thalassaemia carriers has a chance of producing a thalassaemia major baby.
Majority (64.0\%) stated a marriage between a thalassaemia carrier and a normal individual has no chance of producing a thalassaemia major baby. Great majority $(85.2 \%)$ knew that if one blood relative is diagnosed with thalassaemia, other family members should also be screened.

Knowledge on thalassaemia was calculated into scores by adding the number of correct answers given to question 2-12. The study group was divided into two, according to the knowledge score; students with a score of less than $50 \%$ (low score) and a score of more than 50\% (high score). Majority $(83.4 \%)$ had a score of $>50 \%$. When these two groups were compared among the demographic data, age, gender, ethnicity and school type had significant difference $(p<0.05)$ as shown in Table 2. 
Table 2: Distribution of sample on knowledge score by demographic data

\begin{tabular}{|c|c|c|c|c|c|c|c|}
\hline \multicolumn{2}{|c|}{ Variable } & \multicolumn{4}{|c|}{ Knowledge score } & \multirow[t]{2}{*}{ Total } & \multirow[t]{2}{*}{ p-value } \\
\hline & & \multicolumn{2}{|c|}{$>50 \%$} & \multicolumn{2}{|c|}{$<50 \%$} & & \\
\hline \multirow[t]{2}{*}{ Age } & $14-15 y$ & 833 & $79.6 \%$ & 213 & $20.4 \%$ & 1046 & \multirow[t]{2}{*}{$\mathrm{p}<0.05$} \\
\hline & $16-17 y$ & 686 & $88.5 \%$ & 89 & $11.5 \%$ & 775 & \\
\hline \multirow[t]{2}{*}{ Gender } & Female & 956 & $87.6 \%$ & 135 & $12.4 \%$ & 1091 & \multirow[t]{2}{*}{$\mathrm{p}<0.05$} \\
\hline & Male & 563 & $77.1 \%$ & 167 & $22.9 \%$ & 730 & \\
\hline \multirow[t]{4}{*}{ Ethnicity } & Sinhala & 1439 & $84.4 \%$ & 266 & $15.6 \%$ & 1705 & \multirow[t]{4}{*}{$\mathrm{p}<0.05$} \\
\hline & Muslim & 70 & $66.0 \%$ & 36 & $34.0 \%$ & 106 & \\
\hline & Tamil & 08 & $100 \%$ & 0 & 0 & 08 & \\
\hline & Other & 02 & $100 \%$ & 0 & 0 & 02 & \\
\hline \multirow[t]{2}{*}{ School type } & Type 1 & 771 & $85.8 \%$ & 128 & $14.1 \%$ & 899 & \multirow[t]{2}{*}{$\mathrm{p}<0.05$} \\
\hline & Type 2 & 748 & $81.1 \%$ & 174 & $18.9 \%$ & 922 & \\
\hline
\end{tabular}

Schools with all 4 subject streams in grade 12 and 13 (GCE Advanced Level) were classified as "School type 1" and schools without all four subject streams in advanced level classes were classified as "School type 2".

\section{Discussion}

In the present study, the great majority of participants $(92.6 \%)$ had heard of thalassaemia. This was higher than the findings of Mudiyanse et al $(2015)^{8}$ who did a study in Kurunegala to assess the outcome of the project of "safe marriage" and found that $80 \%$ of partners of couples that came for registration of their marriages were aware of thalassaemia. In contrast, similar studies done in neighboring countries have shown lower results. Kukreja et al (2009) ${ }^{9}$ in a Malaysian study to determine awareness of thalassaemia among parents and or married couples of a rural community found that only $46.4 \%$ participants had heard of thalassaemia. In another study done among College students in Saudi Arabia, Olwi et al $(2018)^{10}$ found that only $48 \%$ of students had ever heard of thalassaemia. This could be due to the fact that our study was done in a district with high prevalence of thalassaemia in Sri Lanka and awareness programmes have been done in schools in Kurunegala since 2005.

In the present study the majority $(83.4 \%)$ of students had high $(>50 \%)$ knowledge score and $16.6 \%$ had low $(<50 \%)$ knowledge scores. High level of knowledge reflects good understanding of thalassaemia among the study participants. This may show the success of awareness programmes been done in the district especially in schools and higher education institutes since 2005. Interestingly, knowledge scores between boys and girls varied significantly; in females good knowledge (score $>50 \%$ ) towards thalassaemia was $87.6 \%$ and in males it was $77.1 \%(\mathrm{p}<0.05)$. This is in accordance with the findings of Basu M (2015) ${ }^{11}$ who found that gender was one of the significant contributing factors of knowledge regarding thalassaemia.

Some other parameters also correlated with knowledge. When Sinhalese participants were compared with other ethnicities, there was a statistically significant difference with regards to knowledge $(\mathrm{p}<0.05)$. Age (age group 14-15 years was compared with age group 16-17 years) and school type (type 1 and type 2) also showed statistically significant differences with knowledge $(\mathrm{p}<0.05)$. In contrast, Pujani $\mathrm{M}$ et al $(2017)^{7}$ found that there was no effect of age, gender, region or socio-economic class on the knowledge of thalassaemia among medical students.

The findings of this study will be helpful in improving the quality of thalassaemia awareness and screening programmes done in the island. In Sri Lanka, commonly used languages in the country are Sinhala, Tamil and English. Therefore the programmes should be done in Sinhala, Tamil and English where appropriate to educate the young generation about prevention of thalassaemia. Language should not be a barrier in getting knowledge. Also, Awareness programmes should be done to cover up all the schools in the district with special attention to schools with less facilities.

\section{Conclusions}

Based on study findings, students aged 14-17 years of Kurunegala district, showed satisfactory level of knowledge regarding thalassaemia.

\section{Acknowledgements}

We thank the staff of National Thalassaemia Centre for their assistance and support.

Source of financial support: Research grant Second Health Development Project, Ministry of Health, Sri Lanka.

\section{References}

1. Wetherall DJ, Clegg JB. The thalassaemia syndromes, 4th ed. Oxford: Blackwell Science. 2001.

https://doi.org/10.1002/9780470696705 
2. Rakholia R, Chaturvedi P. Prevalence of $\beta$ thalassemia carrier state in Sindhi community of Wardha and evaluation of risk factors for $\beta$ thalassemia trait. Nigerian Journal of Clinical Practice 2013; 16: 375-80.

https://doi.org/10.4103/1119-3077.113468

PMid: 23771465

3. Premawardhena A, Allen A, Piel F, Fisher C, Perera L, Rodrigo R, et al. The evolutionary and clinical implications of the uneven distribution of the frequency of the inherited haemoglobin variants over short geographical distances. British Journal of Haematology 2016; 176(3), 475-84.

https://doi.org/10.1111/bjh.14437

PMid: 27897311

4. Premawardhana AP, Mudiyanse RA, De Silva ST, Jiffry N, Nelumdeniya U, de Silva U, et al, Nationwide survey of hospital-based thalassemia patients and standards of care and a preliminary assessment of the national prevention program in Sri Lanka. PLOS One 2019; 14(8): e0220852.

https://doi.org/10.1371/journal.pone.0220852

PMid: 31419232 PMCid: PMC6697367

5. De Silva S, Fisher CA, Premawardhene A, Lamabadusuriya SP, Peto TE, Perera G, et al. Thalassaemia in Sri Lanka: implications for the future health burden of Asian populations; Sri Lanka Thalassaemia Study Group. Lancet 2000; 355(9206): 786-91. https://doi.org/10.1016/S0140-6736(99)08246$\mathrm{X}$

6. Dimitris L. Haemoglobinopathies in Greece: prevention programme over the past 35years. Indian Journal of Medical Research 2011; 134(4): 572-6.
7. SPujani M, Chauhan V, Agarwal C, Rana D, Singh K, Dixit S. Knowledge and attitude among Indian medical students towards thalassaemia: a study in Delhi NCR. International Journal of Research in Medical Sciences 2017; 5(10): 4470. https://doi.org/10.18203/23206012.ijrms20174 579

8. Mudiyanse RM. Senanayake MP, Rathnayake RMS. Safe marriages for thalassaemia prevention; A KAP survey in Sri Lanka. Translational Biomedicine 2015: 6(3): https://doi.org/10.21767/2172-0479.100026

9. Kukreja A, Khan A, Xian L, Razley A, Rahim Z. Awareness of thalassaemia among rural folks in Penang, Malaysia. The Internet Journal of Health 2009; 12(1):

10. Olwi DI, Merdad LA, Ramadan EK. Thalassaemia: A prevalent disease yet unknown term among college students in Saudi Arabia. Journal of Community Genetics 2018; 9:277-82.

https://doi.org/10.1007/s12687-017-0351-3

PMid: 29238908 PMCid: PMC6002305

11. Basu M. A study on knowledge, attitude and practice about thalassaemia among general population in outpatient department at a tertiary care hospital, Kolkata. Journal of Preventive Medicine and Holistic Health 2015; 1(1): 5-1 